\title{
Dispersion-tribological property relationship in mineral oils containing 2D layered $\alpha$-zirconium phosphate nanoplatelets
}

\author{
Feng JIANG, Haoyang SUN, Lei CHEN, Fan LEI, Dazhi SUN* \\ Department of Materials Science and Engineering, Southern University of Science and Technology, Shenzhen 518055, China \\ Received: 06 June 2018 / Revised: 07 August 2018 / Accepted: 07 April 2019 \\ (C) The author(s) 2019.
}

\begin{abstract}
Inorganic nanomaterials exhibit superior friction-reduction and anti-wear properties in oils. In this study, 2D layered $\alpha$-zirconium phosphate $(\alpha-\mathrm{ZrP})$ nanosheets intercalated with different amines have been synthesized to study their dispersion stabilities in lubricating oil and tribological applications. The intercalated amines should be sufficiently long and lipophilic to provide stabilization to $\alpha$-ZrP nanosheets in mineral oil. The results of tribological tests illustrate that with the addition of well-dispersed nanosheets, the coefficient of friction (COF) and pin volume loss reduce by $\sim 47 \%$ and $75 \%$, respectively. The excellent dispersion stability enables the nanosheets to flow into the contact area at the beginning, and thereby protect the rubbing surface. A reduction in the van der Waals forces between the adjacent layers induced by the intercalated amines transforms the friction between adjacent layers from pin disk to sliding, leading to a decrease in the COF under hydrodynamic lubrication. The study provides a new method to enhance the tribological properties via tuning the dispersion stabilities of nanomaterials in oils.
\end{abstract}

Keywords: friction-reduction and anti-wear; nanoadditive; layered nanosheet; $\alpha$-zirconium phosphate $(\alpha$-ZrP); dispersion; tribology

\section{Introduction}

Friction and wear in mechanical work generate heat and consume about $30 \%$ of the total energy, which are not favorable for the energy-saving and environmental protection endeavors being carried out [1, 2]. Lubricant additives are commonly added to lubricating oils to enhance the tribological properties and protect the rubbing surfaces [3-13]. Recently developed nanomaterial additives have received extensive interest in the lubrication field because of their superior physical properties, size and shape effects, and unique lubrication mechanisms [10, 14-16]. However, the tendency to aggregate due to the mutual attraction caused by the high surface energies of nanomaterials hampers their stabilization in oils. Usually, electrostatic stabilization and steric stabilization are achieved by tuning the van der Waals attractive forces and electrical double layer repulsive forces, stabilizing the nanomaterials in oils [17, 18]. Therefore, lipophilic surfactants are normally used to disperse nanomaterials in oils $[19,20]$.

Among the various nanomaterials used in lubricating oils, layered $\alpha$-zirconium phosphate $\left(\mathrm{Zr}\left(\mathrm{HPO}_{4}\right)_{2} \cdot \mathrm{H}_{2} \mathrm{O}\right.$, $\alpha-\mathrm{ZrP}$ ) nanosheets (first synthesized by Clearfield and Stynes in 1964 [21] and widely used for multiple applications [22-27]) have received wide research interest for numerous lubrication applications because of their unique 2D layered structures, high purity, and facile surface modifications. For example, He et al. [4] reported that the addition of viscosity-modified $\alpha-\mathrm{ZrP}$ nanosheets into base oil led to friction reduction under hydrodynamic and mixed lubrication conditions, because the addition of nanomaterials led to a decrease in the viscosity of the test oil, and the interactions of the nanomaterials with the oil molecules facilitated

* Corresponding author: Dazhi SUN, E-mail: sundz@sustc.edu.cn 
their entry into the contact area, preventing direct contact. In addition, Ma et al. [28] demonstrated that the anti-wear property and load-carrying capacity of lithium grease significantly improved with the addition of $\alpha$-ZrP nanosheets because of the formation of a tribofilm on the rubbing surface. However, unmodified $\alpha-\mathrm{ZrP}$ nanosheets exhibit poor dispersion in oils, resulting in negative effects on the tribological performance. Although there are several reports on the functionalization of $\alpha-\mathrm{ZrP}$ nanosheets for various applications, the dispersion of modified $\alpha-\mathrm{ZrP}$ nanosheets in oils has not been well studied [29-31].

In this study, we have investigated the dispersion stabilities of $\alpha$-ZrP nanosheets intercalated with amines of different chain lengths (i.e., hexylamine (HA), diglycolamine (DGA), and oleylamine (OA)) in mineral oil. In addition, pin-on-disk tests have been conducted to investigate the tribological performances of pristine and amine-intercalated $\alpha-\mathrm{ZrP}$ nanosheets in mineral oil. The effects of amine-intercalated $\alpha$-ZrP nanosheets on the coefficient of friction (COF) and pin volume loss values of the oil dispersions have been systematically studied. Moreover, we have optimized the concentration of the amine-intercalated $\alpha-\mathrm{ZrP}$ nanosheets added to mineral oil. The mechanism of enhancement of tribological properties has been discussed, as well.

\section{Experimental details}

\subsection{Synthesis of pristine $\alpha-Z r P$ nanosheets}

Phosphoric acid (AR reagent grade), zirconium oxychloride (98\%), HA (99\%), DGA (98\%), and OA $(80 \%-90 \%)$ were purchased from Aladdin and mineral oil (150 N with a viscosity of 30-34 mPa.s) was directly bought from the commercial market. All chemicals were used without further purification. Lamellar structured $\alpha-\mathrm{ZrP}$ nanosheets were synthesized by the method described by Sun et al. [32]. Briefly, $15 \mathrm{~g}$ $\mathrm{ZrOCl}_{2} \cdot 8 \mathrm{H}_{2} \mathrm{O}$ was added to a Teflon-lined pressure vessel containing $150 \mathrm{~mL}$ of $9 \mathrm{~mol} / \mathrm{L}$ phosphoric acid. The slurry was then heated in an oven at $200{ }^{\circ} \mathrm{C}$ for $24 \mathrm{~h}$. After the reaction, the sample was rinsed with deionized water and isolated by centrifugation three times. The final product was dried in an oven at $65{ }^{\circ} \mathrm{C}$ for $24 \mathrm{~h}$ and ground into a fine powder. This sample was designated as pristine $\alpha$-ZrP nanosheets.

\subsection{Preparation of amine-intercalated $\alpha-\mathrm{ZrP}$ nanosheets in mineral oil}

The intercalation of HA, DGA, and OA into $\alpha-\mathrm{ZrP}$ nanosheets was performed according to the procedure reported by Alberti and Costantino [33], with slight modification. Typically, $1 \mathrm{~g} \alpha$-ZrP nanosheets was dispersed in $60 \mathrm{~mL}$ alcohol. Then, the amines were added to the $\alpha-\mathrm{ZrP}$ nanosheet dispersion, separately; the molar ratio of amine to $\alpha$-ZrP nanosheets was set as 2.5:1 to achieve complete intercalation. The resulting mixtures were stirred at room temperature at $600 \mathrm{rpm}$ for $6 \mathrm{~h}$. The obtained products were rinsed with petroleum ether three times and dried at $65{ }^{\circ} \mathrm{C}$ for $24 \mathrm{~h}$. The as-prepared intercalated samples were designated as HA_ $\alpha-Z r P$, DGA_ $\alpha-Z r P$, and OA_ $\alpha-Z r P$ nanosheets.

The obtained amine-intercalated $\alpha$-ZrP nanosheets were ground into fine powders and directly mixed with mineral oil to obtain samples with various concentrations. To obtain homogeneous dispersions, the oil mixtures were sonicated for about $30 \mathrm{~min}$ before use.

\subsection{Tribological tests}

The COF, wear scar diameter (WSD), and pin volume loss (derived from WSD) [34] were evaluated using a Bruker's Universal Mechanical Tester (UMT-2, Germany) in the pin-on-disk mode. Specifically, the configuration consisted of a disk (E52 100 steel with a diameter of $70.00 \mathrm{~mm}$ ) and a fixed pin (E52 100 steel with a diameter of $6.35 \mathrm{~mm}$ ); the disk and ball were washed with petroleum ether before each test. The rotation speed was $200 \mathrm{rpm}$ and the length from the center to the contact spot was $23 \mathrm{~mm}$. Typically, $25 \mathrm{~mL}$ sample was added to completely immerse the ball before the friction test; each test was conducted three times for error minimization under a normal load of $10 \mathrm{~N}$ for $6 \mathrm{~h}$ at an ambient environment. The schematic of the tribological test setup is presented in Fig. 1.

\subsection{Characterization}

Powder X-ray diffraction (XRD) patterns were collected on a Rigaku Smartlab instrument using the $\mathrm{Cu} \mathrm{K \alpha}$ 


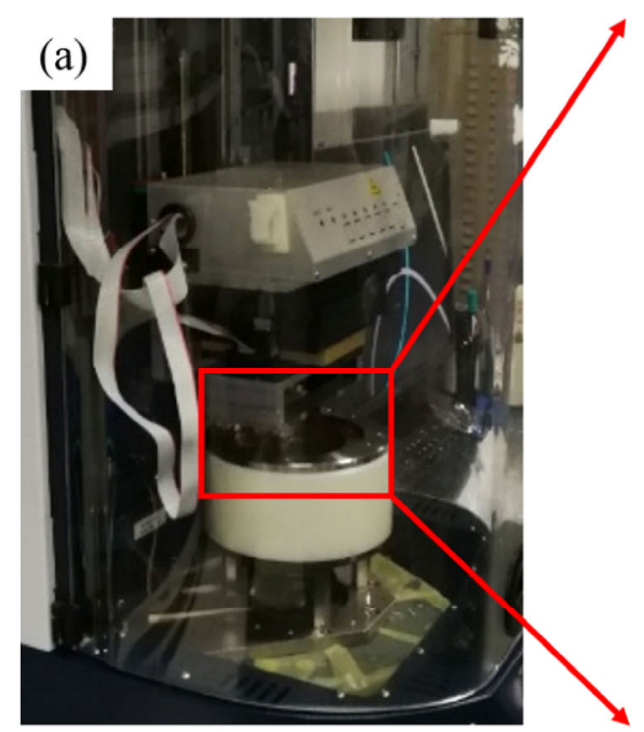

(b)

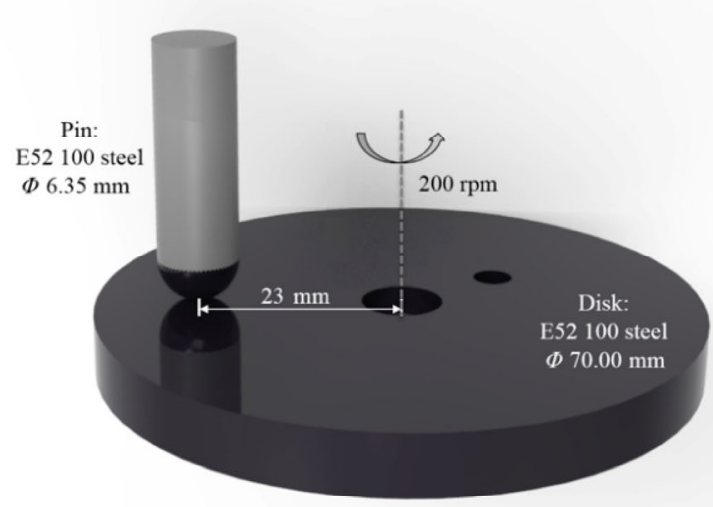

Fig. 1 Tribological setup: (a) photograph of the testing apparatus and (b) schematic of the pin-on-disk tribological equipment.

radiation at $45 \mathrm{kV}$ and $200 \mathrm{~mA}$ in the scanning angle range from $2^{\circ}$ to $60^{\circ}$ to evaluate the interspace of the intercalated $\alpha$-ZrP nanosheets containing different amines, as well as pristine $\alpha-Z r P$ nanosheets. Field emission scanning electron microscope (FESEM, TESCAN Vega 3, the Czech Republic) was used to observe the morphologies of the synthesized $\alpha-\mathrm{ZrP}$ nanosheets and worn surfaces of the steel ball. The intercalation of amines and the amounts intercalated into the $\alpha$-ZrP nanosheets were investigated by Fouriertransform infrared spectroscopy (FT-IR Spectrum TWO, PerkinElmer Co., Ltd.) and thermogravimetric analysis (TGA, METTLER) at a heating rate of $10{ }^{\circ} \mathrm{C}$ per minute from 60 to $800{ }^{\circ} \mathrm{C}$, respectively.

\section{Results and discussion}

\subsection{Characterization of pristine and amine- intercalated $\alpha-Z r P$ nanosheets}

The morphologies of pristine and modified $\alpha-\mathrm{ZrP}$ nanosheets were characterized by FESEM; the FESEM images are shown in Fig. 2. The pristine $\alpha$-ZrP nanosheets (Fig. 2(a)) are nearly hexagonal and lamellar structured, indicating high crystallinity. The average size and thickness values (Table 1) of the pristine and amine-intercalated $\alpha$-ZrP nanosheets were determined from numerous FESEM images by randomly examining 100 individual nanosheets. As observed, the sizes
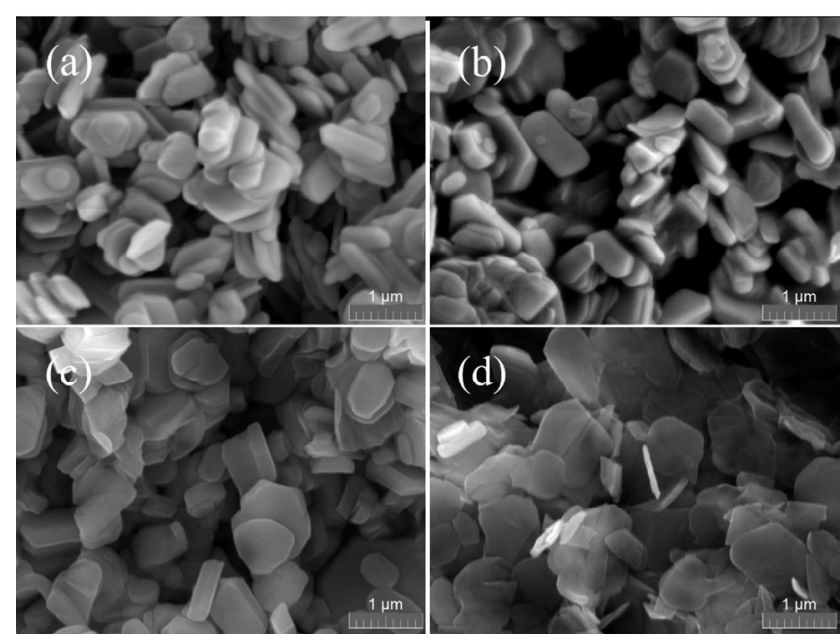

Fig. 2 FESEM images of (a) pristine $\alpha$-ZrP, (b) HA $\alpha-Z r P$, (c) DGA_ $\alpha-Z r P$, and (d) OA_ $\alpha-Z r P$ nanosheets.

Table 1 Average size and thicknesses of pristine and amineintercalated $\alpha-\mathrm{ZrP}$ nanosheets.

\begin{tabular}{|c|c|c|c|}
\hline Sample & $\begin{array}{c}\text { Average size } \\
a / \mathrm{nm}\end{array}$ & $\begin{array}{c}\text { Average thickness } \\
h / \mathrm{nm}\end{array}$ & $\begin{array}{l}\text { Aspect } \\
\text { ratio } a / h\end{array}$ \\
\hline Pristine $\alpha-\mathrm{ZrP}$ & $830 \pm 203$ & $111 \pm 27$ & 7.5 \\
\hline HA_ $\alpha-Z r P$ & $821 \pm 155$ & $182 \pm 53$ & 4.5 \\
\hline DGA_ $\alpha-Z r P$ & $792 \pm 208$ & $184 \pm 40$ & 4.3 \\
\hline OA_ $\alpha-Z r P$ & $847 \pm 230$ & $69 \pm 10$ & 12.3 \\
\hline
\end{tabular}

of amine-intercalated $\alpha$-ZrP nanosheets and pristine $\alpha-\mathrm{ZrP}$ nanosheets are nearly the same $(\sim 830 \mathrm{~nm})$; however, their thicknesses are different. The average thicknesses of HA_ $\alpha-Z r P(\sim 182 \mathrm{~nm})$ and DGA_ $\alpha-Z r P$ 
$(\sim 184 \mathrm{~nm})$ nanosheets are higher than that of pristine $\alpha$-ZrP nanosheets $(\sim 111 \mathrm{~nm})$ because of the intercalation of amines into pristine nanosheets, leading to a decrease in the aspect ratio from $\sim 7.5$ (pristine $\alpha$-ZrP nanosheets) to 4.5 (HA_ $\alpha-Z r P$ ) and 4.3 (DGA_ $\alpha-Z r P$ ). However, the average thickness of OA_ $\alpha-Z r P$ nanosheets $(\sim 69 \mathrm{~nm})$ is $\sim 38 \%$ lower than that of pristine $\alpha$-ZrP nanosheets $(\sim 111 \mathrm{~nm})$. This is possibly due to the fact that the intercalation of the relatively long OA molecules into pristine $\alpha$-ZrP nanosheets significantly increases the interspace, leading to a decrease in the van der Waals attractive forces between the adjacent layers and further exfoliation into thinner nanosheets as compared to pristine $\alpha-\mathrm{ZrP}$ nanosheets.

The FT-IR spectra of pristine and amine-intercalated $\alpha-\mathrm{ZrP}$ nanosheets are displayed in Fig. 3 , which confirm the intercalation of amines into the $\alpha$-ZrP layers. In the FT-IR spectra, the bands at 3,504 and 3,588 $\mathrm{cm}^{-1}$ (region 1 in Fig. 3) are assigned to the stretching and vibration modes of $\mathrm{O}-\mathrm{H}$, indicating the presence of crystalline water in the pristine and amine-intercalated $\alpha$-ZrP nanosheets. However, a decrease in the relative transmittance in this region for amine-intercalated $\alpha-\mathrm{ZrP}$ nanosheets reveals that the intercalation of amine molecules into the $\alpha-\mathrm{ZrP}$ nanosheets reduces the amount of crystalline water in the interlayers. The band ranging from 900 to $1,200 \mathrm{~cm}^{-1}$, which is indicated in region 2 in Fig. 3, corresponds to the symmetric $\mathrm{P}-\mathrm{O}$ stretching mode of $\alpha-\mathrm{ZrP}$, demonstrating that the amine intercalation does not change the inner

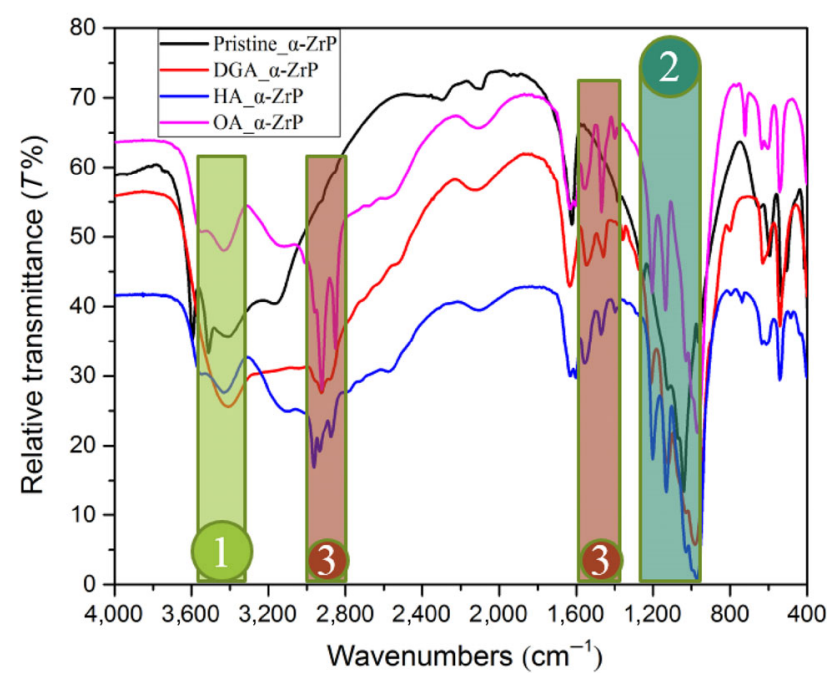

Fig. 3 FT-IR spectra of pristine and amine-intercalated $\alpha-\mathrm{ZrP}$ nanosheets. molecular scaffold of $\alpha-Z r P$ nanoplatelets. Moreover, the amine-intercalated $\alpha-Z r P$ nanosheet samples exhibit new bands at 1,450-1,550 and 2,800-2,900 $\mathrm{cm}^{-1}$ (region 3 in Fig. 3), which are associated with the stretching modes of $\mathrm{C}-\mathrm{H}$ and $\mathrm{N}-\mathrm{H}$. This demonstrates the successful intercalation of amine molecules into the $\alpha$-ZrP interlayers $[35,36]$.

TGA was conducted to determine the amounts of amines intercalated into the $\alpha-\mathrm{ZrP}$ nanosheets. Figure 4 reveals the weight loss (percent) values of pristine and amine-intercalated $\alpha$-ZrP nanosheets. The weight loss curve of pristine $\alpha-\mathrm{ZrP}$ nanosheets shows two main weight-loss steps below 250 and $700{ }^{\circ} \mathrm{C}$; the total weight loss for pristine $\alpha$-ZrP nanosheets is about $9.5 \%$. In the first stage, the weight loss is attributed to the removal of free water and crystalline water from the interlayers. In the second stage, the weight loss below $700{ }^{\circ} \mathrm{C}$ is attributed to the condensation of adjacent layers, illustrating the high thermal stability of $\alpha$-ZrP nanosheets [4]. The amine-intercalated $\alpha-\mathrm{ZrP}$ nanosheets: HA_ $\alpha-Z r P$, DGA_ $\alpha-Z r P$, and OA_ $\alpha-Z r P$ nanosheets exhibit different thermal stabilities because they contain different amines, and the respective total weight loss values (after $700{ }^{\circ} \mathrm{C}$ ) are $43.5,38.1$, and 64.0, respectively. The intercalation amounts of amines for HA_ $\alpha$-ZrP, DGA_ $\alpha-Z r P$, and OA_ $\alpha$-ZrP are determined to be $37.6 \%, 21.6 \%$, and $60.2 \%$, respectively. Considering the amounts of intercalated amine molecules and pristine $\alpha-\mathrm{ZrP}$ nanosheets used, it can be concluded that for the HA_ $\alpha-Z r P$, DGA_ $\alpha-Z r P$, and OA_ $\alpha-Z r P$

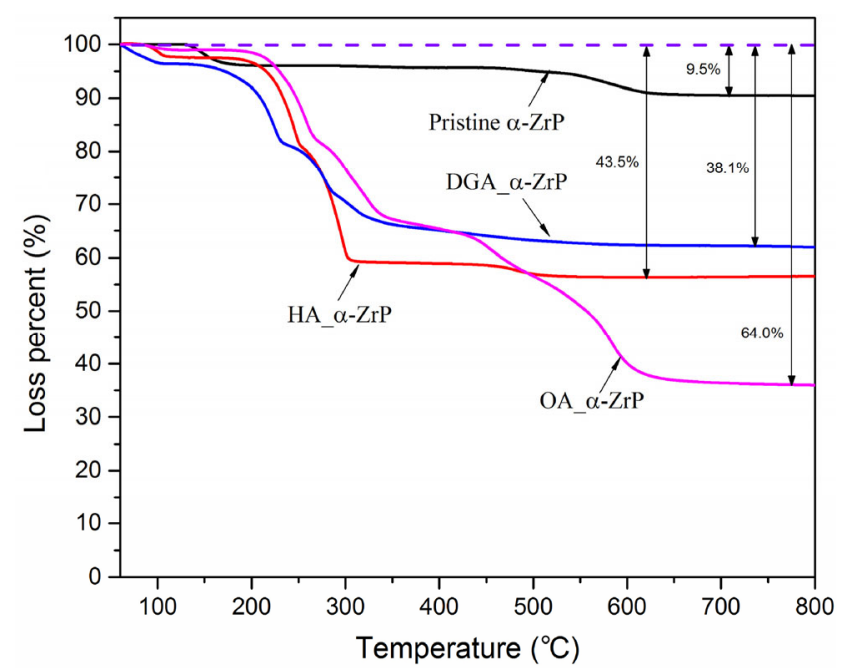

Fig. 4 TGA curves of pristine and amine-intercalated $\alpha-\mathrm{ZrP}$ nanosheets. 
nanosheets, the molar ratios between amines and $\alpha-\mathrm{ZrP}$ are $\sim 1.8,1.5$, and 1.7 , respectively.

The lattice spacings of pristine and amine-intercalated $\alpha$-ZrP nanosheets were determined by XRD; the XRD patterns are shown in Fig. 5. The diffraction peaks at $2 \theta$ of $11.66^{\circ}, 19.80^{\circ}$, and $24.96^{\circ}$ for pristine $\alpha-\mathrm{ZrP}$ nanosheets are assigned to the (002), (110), and (112) planes, respectively. In terms of pristine $\alpha$-ZrP nanosheets, the (002) plane reflects the lattice spacing between the adjacent layers. According to the Bragg equation, the lattice spacing $d$ is $7.6 \AA$, which is consistent with Ref. [24]. Similarly, the lattice spacings of amine-intercalated $\alpha-\mathrm{ZrP}$ nanosheets were determined from the corresponding XRD peaks. According to the X-ray scattering theory by Saunders et al. [37], the intercalated lamellar structures should show a series of diffraction peaks, which indicate high structural integrity in the $z$ direction. For DGA_ $\alpha-Z r P$ nanosheets, diffraction peaks are observed at $2 \theta$ of $4.50^{\circ}, 9.02^{\circ}$, and $13.58^{\circ}$, corresponding to $d$ values of 19.6, 9.8, and $6.5 \AA$, respectively. The ratio of the reciprocal $d$ values $(1 / 19.6: 1 / 9.8: 1 / 6.5)$ is approximately $1: 2: 3$, indicating that the lattice spacing for DGA_ $\alpha-Z r P$ nanosheets is $19.6 \AA$. The XRD pattern of HA_ $\alpha-Z r P$ nanosheets is similar to that of DGA_ $\alpha-Z r P$ nanosheets, and the ratio of the reciprocal $d$ values $(1 / 23.4: 1 / 11.6: 1 / 7.8)$ is approximately $1: 2: 3$, indicating

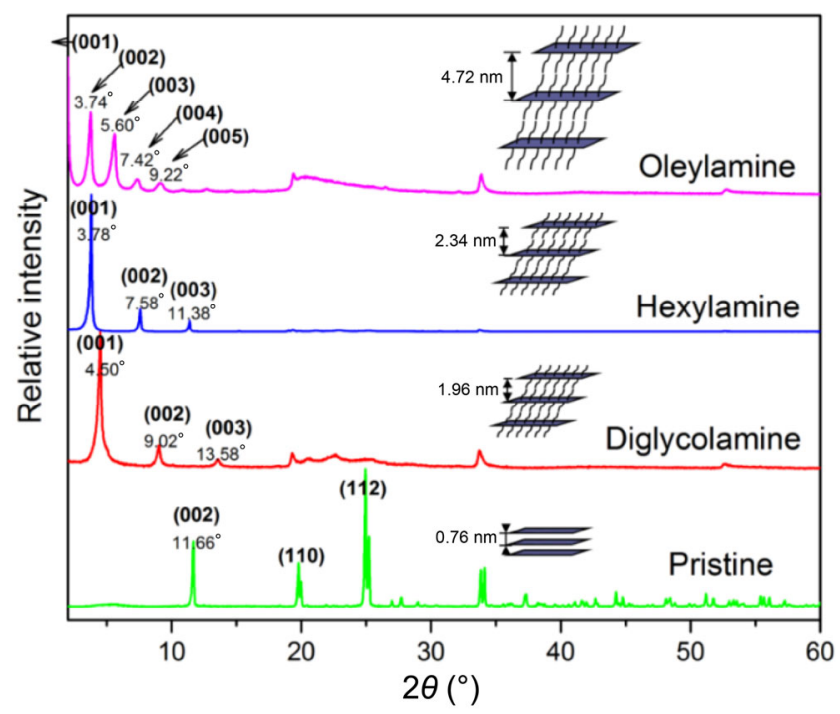

Fig. 5 XRD patterns of pristine $\alpha-\mathrm{ZrP}$ nanosheets and $\alpha-\mathrm{ZrP}$ nanosheets intercalated by diglycolamine, hexylamine, and oleylamine, respectively. Insets: schematics illustrating the intercalated structures and lattice spacings. that the interspacing for HA_ $\alpha-Z r P$ nanosheets is $23.4 \AA$, which is larger than that for DGA_ $\alpha-\mathrm{ZrP}$ nanosheets. For OA_ $\alpha$-ZrP nanosheets, the $d$ values corresponding to $2 \theta=3.74^{\circ}, 5.60^{\circ}, 7.42^{\circ}$, and $9.22^{\circ}$ are $23.6,15.8,11.9$, and $9.6 \AA$, respectively, and the ratio of the reciprocal $d$ values $(1 / 23.6: 1 / 15.8: 1 / 11.9: 1 / 9.6)$ is approximately $2: 3: 4: 5$, which shows that the lattice spacing $d$ is approximately $47.2 \AA$ (twice of $23.6 \AA$ ). By comparing the XRD patterns of all the samples, we can conclude that the interlayer spacings of the amine-intercalated $\alpha-\mathrm{ZrP}$ nanosheets are strongly affected by the chain lengths of the amine molecules, and the longer the amine molecules, the larger the interspacing is.

Intercalation of $\alpha$-ZrP nanosheets with different amines not only results in different interlayer spacings, but also leads to different dispersion stabilities in oils, which will be discussed in the following section.

\subsection{Dispersion tests}

Figure 6 presents the photographs of $1.0 \mathrm{wt} \%$ pristine and amine-intercalated $\alpha-Z r P$ nanosheets in mineral oil. The pristine $\alpha-Z r P$ nanosheets do not show any solubility in oil, as expected. As observed, the oil suspension containing $\alpha-\mathrm{ZrP}$ nanosheets intercalated by $\mathrm{OA}$ is more stable (with no visible sedimentation) than HA_ $\alpha-Z r P$ and DGA_ $\alpha-Z r P$ nanosheet suspensions after one week. DGA_ $\alpha-Z$ rP nanosheets exhibit extremely low dispersibility in mineral oil and settle down at the bottom immediately after mixing. HA_ $\alpha-Z r P$ nanosheets exhibit relatively good dispersion at first; however, they start to delaminate after a few hours.

The difference in dispersion stabilities of various $\alpha-\mathrm{ZrP}$ nanosheets is mainly attributed to the intercalated amine molecules. The schematics showing the proposed mechanisms illustrating the different dispersion stabilities of pristine and amine-intercalated $\alpha-\mathrm{ZrP}$ nanosheets in mineral oil are presented in Fig. 7 . Specifically, because pristine $\alpha-Z r P$ nanosheets are purely inorganic, they are immiscible with the organic oil molecules, as illustrated in Fig. 7(a). OA has a C-18 alkyl chain with an amine group at the end and a double bond in the middle. The long alkyl OA molecules exhibit strong attraction to mineral oil molecules, and they significantly increase the interlayer 


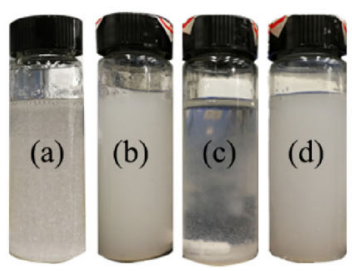

Original
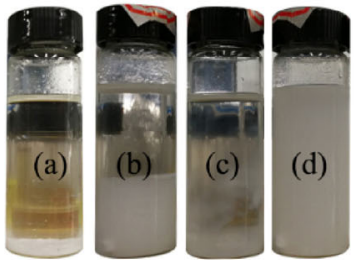

$2 \mathrm{~d}$
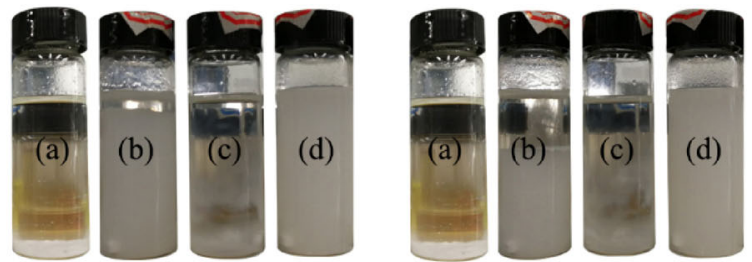

$6 \mathrm{~h}$

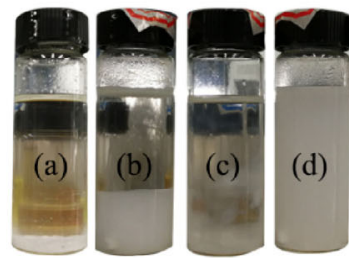

$4 \mathrm{~d}$
$1 \mathrm{~d}$

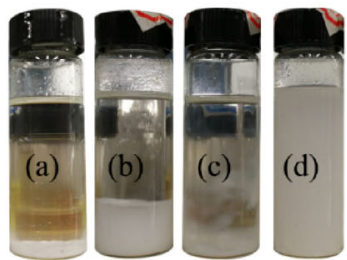

$1 \mathrm{w}$

Fig. 6 Dispersion test results: photographs of $1.0 \mathrm{wt} \%$ (a) pristine $\alpha-Z r P$, (b) HA_ $\alpha-Z r P$, (c) DGA_ $\alpha-Z r P$, and (d) OA_ $\alpha-Z r P$ nanosheets in mineral oil.

(a)

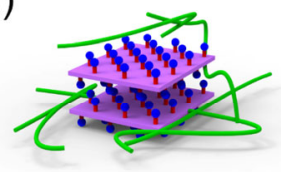

(c)

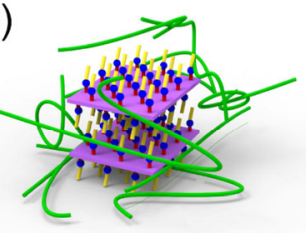

(b)

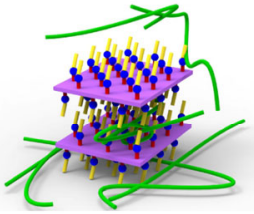

(d)

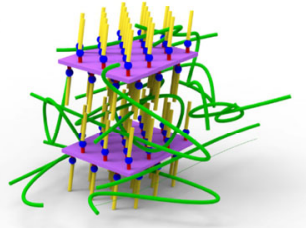

Fig. 7 Schematics of dispersion of (a) pristine $\alpha-\mathrm{ZrP}$, (b) HA_ $\alpha-Z r P$, (c) DGA_ $\alpha-Z r P$, and (d) OA_ $\alpha-Z r P$ nanosheets in mineral oil.

spacing of pristine $\alpha-\mathrm{ZrP}$ nanosheets by interaction. Because of the large interspacing, the oil molecules enter the interlayers, thus further improving the dispersion stability of OA_ $\alpha-Z r P$ nanosheets in mineral oil, as illustrated in Fig. 7(d). On the other hand, DGA is a polar molecule, which is immiscible with mineral oil molecules, resulting in an extremely low dispersion stability, as illustrated in Fig. 7(c). In addition, the interspace of HA_ $\alpha-\mathrm{ZrP}$ nanosheets is not sufficiently large for the entry of several mineral oil molecules into the interlayers, eventually leading to phase separation, as illustrated in Fig. 7(b). Therefore, the two criteria for choosing a suitable dispersant to stabilize $\alpha-Z r P$ nanosheets in oil are: (1) the dispersant should be amphiphilic, e.g., alkylamine, and (2) the

amine chain should be longer than the oil molecules for large interspace creation to permit the oil molecules to enter the interlayers.

\subsection{Tribological tests}

Tribological tests were carried out on pure mineral oil and oil dispersions containing pristine $\alpha-\mathrm{ZrP}$, HA_ $\alpha-Z r P$, DGA_ $\alpha-Z r P$, and OA_ $\alpha-Z r P$ nanosheets at $0.5,1.0,1.5$, and $2.0 \mathrm{wt} \%$ under a normal load of $10 \mathrm{~N}$ at $200 \mathrm{rpm}$ and room temperature for $6 \mathrm{~h}$. The COF vs. concentration plots are displayed in Fig. 8.

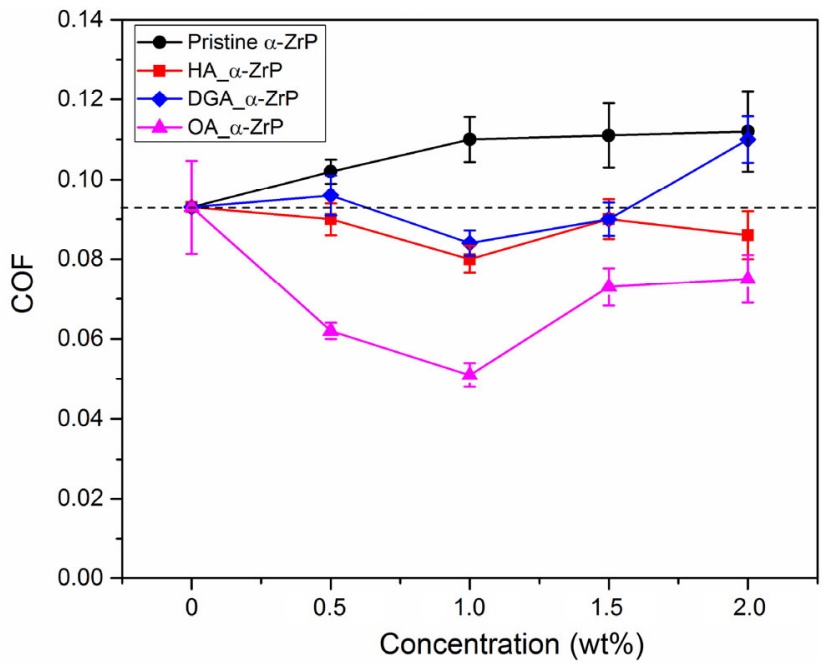

Fig. 8 Coefficient of friction as a function of concentration for pristine $\alpha-Z r P$, HA_ $\alpha-Z r P$, DGA_ $\alpha-Z r P$, and OA_ $\alpha-Z r P$ nanosheets in mineral oil. The dotted line represents the value for the pure mineral oil. 
As shown in Fig. 8, all the oils containing pristine $\alpha$-ZrP nanosheets exhibit higher COFs than the pure mineral oil. With increase in the concentration of pristine $\alpha$-ZrP nanosheets in mineral oil from 0 to $2.0 \mathrm{wt} \%$, the COF gradually increases from $\sim 0.09$ to 0.11 , indicating that the unmodified $\alpha-\mathrm{ZrP}$ nanosheets are unsuitable for friction reduction in the oil medium, which is likely due to their poor dispersion. For HA_ $\alpha$-ZrP nanosheets, the COF ranges $\sim 0.08$ to $\sim 0.09$ as a function of the concentration; the values are slightly lower than that for pure mineral oil, indicating that the COF of mineral oil does not significantly reduce in the presence of HA_ $\alpha-\mathrm{ZrP}$ nanosheets. The COF of the DGA_ $\alpha-Z r P$ nanosheets in mineral oil at $0.5 \mathrm{wt} \%$ is slightly higher than that of pure mineral oil, and then it drops to $\sim 0.08$ at $1.0 \mathrm{wt} \%$. When the concentration of DGA_ $\alpha$-ZrP nanosheets in mineral oil reaches $2.0 \mathrm{wt} \%$, the COF increases to $\sim 0.11$, which is higher than that of pure mineral oil. This indicates that DGA_ $\alpha-Z r P$ nanosheets do not function well as a lubricant additive in mineral oil because of their severe aggregation and poor dispersion. On the other hand, when OA_ $\alpha$-ZrP nanosheets are added to mineral oil, the COF significantly reduces. With increase in the concentration of OA_ $\alpha-\mathrm{ZrP}$ nanosheets in mineral oil from 0 to $1.0 \mathrm{wt} \%$, the COF gradually decreases from $\sim 0.09$ to $\sim 0.05$, corresponding to a significant friction reduction of $\sim 47 \%$. Subsequently, with increase in the OA_ $\alpha-Z r P$ concentration to $>1.0 \mathrm{wt} \%$, the COF increases to $\sim 0.07$, which is lower than that of pure mineral oil. It should be noted that all amineintercalated $\alpha$-ZrP nanosheets in mineral oil exhibit minimum COFs at $1.0 \mathrm{wt} \%$, which is determined to be the optimized concentration of modified $\alpha-\mathrm{ZrP}$ nanosheets for friction-reduction applications. However, further increase in the concentrations of amineintercalated $\alpha$-ZrP nanosheets in mineral oil leads to an increase in the COFs, which is attributed to the concentration-induced flocculation and aggregation of nanosheets.

The WSD and pin volume loss values for pure mineral oil and mineral oils containing different concentrations of amine-intercalated $\alpha$-ZrP nanosheets are presented in Table 2. To compare the tribological performances of pristine and amine-intercalated $\alpha-\mathrm{ZrP}$ nanosheets, the pin volume loss was plotted as a function of concentration, as displayed in Fig. 9.
Pure mineral oil shows an average pin volume loss of $\sim 4.8 \times 10^{-11} \mathrm{~m}^{3}$ under our testing condition. The pin volume loss for the oil dispersion with $0.5 \mathrm{wt} \%$ of pristine $\alpha$-ZrP nanosheets is $\sim 7.3 \times 10^{-11} \mathrm{~m}^{3}$, which is $\sim 52 \%$ higher than that for pure mineral oil; the value

Table 2 WSD and pin volume loss values for pure mineral oil and mineral oil dispersions containing different concentrations of pristine and amine-intercalated $\alpha$-ZrP nanosheets.

\begin{tabular}{|c|c|c|}
\hline Sample & $\begin{array}{l}\text { WSD } \\
(\mu \mathrm{m})\end{array}$ & $\begin{array}{l}\text { Pin volume loss } \\
\qquad\left(\times 10^{-11} \mathrm{~m}^{3}\right)\end{array}$ \\
\hline Pure mineral oil & $1323 \pm 34$ & $4.8 \pm 0.6$ \\
\hline $0.5 \mathrm{wt} \%$ pristine $\alpha-\mathrm{ZrP}$ & $1469 \pm 22$ & $7.3 \pm 0.4$ \\
\hline $0.5 \mathrm{wt} \%$ HA_ $\alpha-\mathrm{ZrP}$ & $1371 \pm 31$ & $5.5 \pm 0.5$ \\
\hline $0.5 \mathrm{wt} \%$ DGA_ $\alpha-\mathrm{ZrP}$ & $1640 \pm 11$ & $11.4 \pm 0.3$ \\
\hline $0.5 \mathrm{wt} \%$ OA_ $\alpha-\mathrm{ZrP}$ & $1382 \pm 24$ & $5.7 \pm 0.4$ \\
\hline $1.0 \mathrm{wt} \%$ pristine $\alpha-\mathrm{ZrP}$ & $1584 \pm 37$ & $9.9 \pm 0.9$ \\
\hline $1.0 \mathrm{wt} \%$ HA_ $\alpha-\mathrm{ZrP}$ & $1172 \pm 37$ & $2.9 \pm 0.3$ \\
\hline $1.0 \mathrm{wt} \%$ DGA_ $\alpha-\mathrm{ZrP}$ & $1834 \pm 17$ & $18.0 \pm 0.7$ \\
\hline $1.0 \mathrm{wt} \%$ OA_ $\alpha-\mathrm{ZrP}$ & $948 \pm 13$ & $1.2 \pm 0.1$ \\
\hline $1.5 \mathrm{wt} \%$ pristine $\alpha-\mathrm{ZrP}$ & $1564 \pm 42$ & $9.4 \pm 1.1$ \\
\hline $1.5 \mathrm{wt} \%$ HA_ $\alpha-\mathrm{ZrP}$ & $1189 \pm 39$ & $3.1 \pm 0.4$ \\
\hline $1.5 \mathrm{wt} \%$ DGA_ $\alpha-\mathrm{ZrP}$ & $1828 \pm 21$ & $17.8 \pm 0.9$ \\
\hline $1.5 \mathrm{wt} \%$ OA_ $\alpha-\mathrm{ZrP}$ & $1158 \pm 33$ & $2.8 \pm 0.5$ \\
\hline $2.0 \mathrm{wt} \%$ pristine $\alpha-\mathrm{ZrP}$ & $1578 \pm 76$ & $9.8 \pm 1.8$ \\
\hline $2.0 \mathrm{wt} \%$ HA_ $\alpha-\mathrm{ZrP}$ & $1376 \pm 56$ & $5.6 \pm 1.1$ \\
\hline $2.0 \mathrm{wt} \%$ DGA_ $\alpha-\mathrm{ZrP}$ & $1780 \pm 33$ & $15.9 \pm 1.2$ \\
\hline $2.0 \mathrm{wt} \%$ OA_ $\alpha-\mathrm{ZrP}$ & $1399 \pm 78$ & $6.0 \pm 1.3$ \\
\hline
\end{tabular}

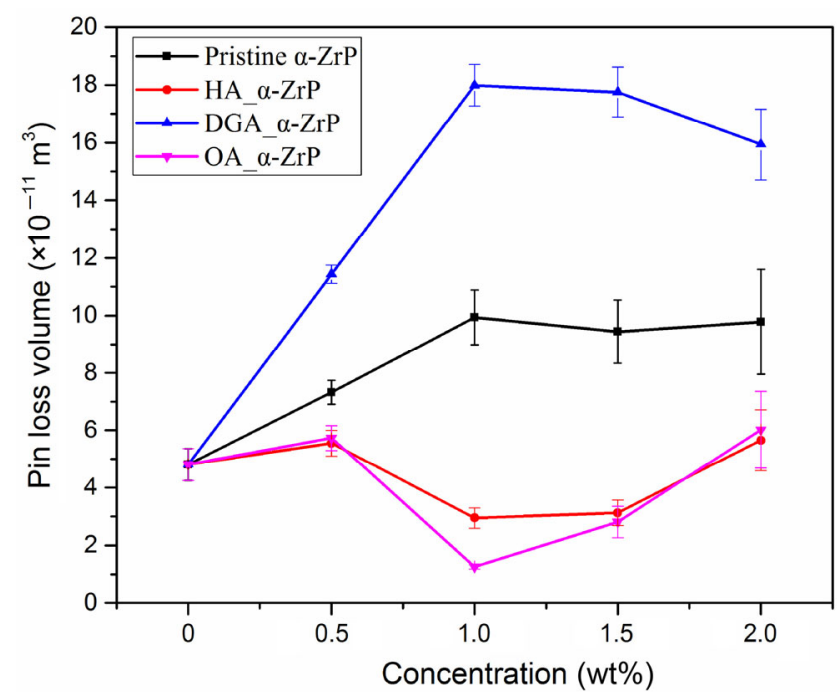

Fig. 9 Pin volume loss as a function of concentration for pristine $\alpha-Z r P, H A \_\alpha-Z r P$, DGA_ $\alpha-Z r P$, and OA_ $\alpha-Z r P$ nanosheets in mineral oil. 
fluctuates at $\sim 9.5 \times 10^{-11} \mathrm{~m}^{3}$ as the concentration increases from 1.0 to $2.0 \mathrm{wt} \%$, which is $\sim 98 \%$ higher than that for pure mineral oil. Similarly, the pin volume loss values for the oil dispersions containing DGA_ $\alpha-Z r P$ nanosheets are larger than that for pure mineral oil. The maximum value of pin volume loss for the oil dispersion containing $1.0 \mathrm{wt} \%$ DGA_ $\alpha-\mathrm{ZrP}$ nanosheet is $\sim 17.9 \times 10^{-11} \mathrm{~m}^{3}$, which is $\sim 274 \%$ higher than that for pure mineral oil. Thus, pristine and DGA_ $\alpha$-ZrP nanosheets exhibit very poor anti-wear properties in mineral oil, which are attributed to their poor dispersibilities in mineral oil, as illustrated in Fig. 6 . Both pristine and DGA_ $\alpha-Z r P$ nanosheets form large aggregates in mineral oil because of their strong intralayer interactions and poor miscibilities with oil molecules, resulting in large-scale damages of the worn surfaces. On the other hand, the pin volume loss values for 1.0 and $1.5 \mathrm{wt} \%$ of HA_ $\alpha$-ZrP nanosheets in mineral oil are $2.9 \times 10^{-11}$ and $3.1 \times 10^{-11} \mathrm{~m}^{3}$, respectively, which are $\sim 38 \%$ smaller than that for pure mineral oil. When the concentration of the HA_ $\alpha$-ZrP nanosheets is relatively low $(0.5 \mathrm{wt} \%)$, or high $(2.0 \mathrm{wt} \%)$, the oil dispersion shows a pin volume loss very similar to that for the pure mineral oil. The oil dispersion containing $0.5 \mathrm{wt} \%$ of OA_ $\alpha-\mathrm{ZrP}$ nanosheets shows a pin volume loss slightly higher than that of the pure mineral oil. However, with increase in the concentration to $1.0 \mathrm{wt} \%$, the pin volume loss considerably decreases to $\sim 1.2 \times 10^{-11} \mathrm{~m}^{3}$, which is the highest reduction ( $75 \%)$ in pin volume loss among that observed for all oil dispersion samples. As the concentration of OA_ $\alpha-Z r P$ nanosheets in mineral oil further increases, the pin volume loss gradually increases, indicating that OA_ $\alpha-\mathrm{ZrP}$ at significantly high concentration in mineral oil can lead to surface damages.

The tribological studies show that HA_ $\alpha-Z r P$ and OA_ $\alpha$-ZrP nanosheets, which are highly dispersible in mineral oil, can efficiently reduce the pin volume loss and COF than pristine and DGA_ $\alpha-Z r P$ nanosheets, which have low dispersibilities, demonstrating the importance of dispersion stability on the tribological performances of lubricating oils containing inorganic nanomaterials. It should also be noted that the highest reduction in the $\mathrm{COF}$ and pin volume loss is observed for the dispersion containing $1.0 \mathrm{wt} \%$ of OA_ $\alpha-Z r P$ nanosheets. Moreover, the oil dispersion containing OA_ $\alpha-\mathrm{ZrP}$ nanosheets exhibits smaller data fluctuations (errors) in COF values than the mineral oil, indicating that the as-prepared $\alpha-\mathrm{ZrP}$ nanosheets can improve the operational stabilities and performances of lubricating oils for practical applications.

To investigate the detailed tribological performances of pristine and amine-intercalated $\alpha-\mathrm{ZrP}$ nanosheets in mineral oil, COFs for pure mineral oil and oil dispersions containing pristine and amine-intercalated $\alpha-\mathrm{ZrP}$ nanosheets were plotted as a function of time for a $6 \mathrm{~h}$ test, as presented in Fig. 10. The COF for pure mineral oil significantly fluctuates at a relatively high value of $\sim 0.15$ within the first 5,000 s of the test. This is attributed to the fact that at the beginning of the friction process, the contact area between the friction pairs is small to support the load, resulting in a relatively high contact pressure. In the next stage, from 5,000 to $15,000 \mathrm{~s}$, the COF for pure mineral oil gradually decreases from $\sim 0.15$ to $\sim 0.09$ and remains at $\sim 0.09$ until the end of the test. This is because during the friction process, the wear scar becomes sufficiently large to support the load, and the friction is mostly the internal friction of the fluid [38]. However, until $5,000 \mathrm{~s}$, the COF for the oil dispersion with pristine $\alpha-\mathrm{ZrP}$ nanosheets is found to be $\sim 13 \%$ higher than that for pure mineral oil, which indicates the formation of large aggregates of poorly dispersed pristine $\alpha$-ZrP nanosheets, leading to an increase in friction between the rubbing surfaces. For dispersions with

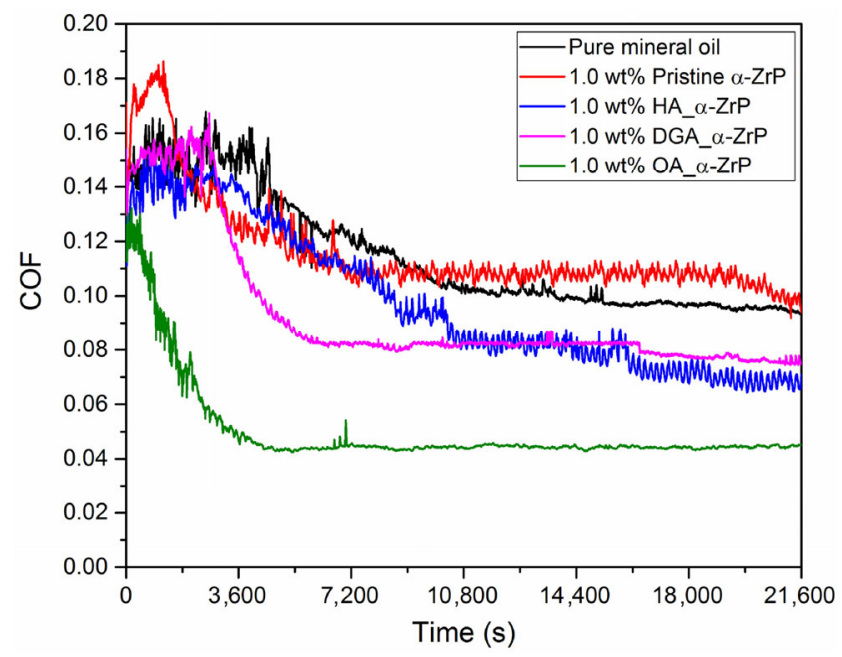

Fig. 10 Coefficient of friction as a function of time for pure mineral oil and mineral oil dispersions with $1.0 \mathrm{wt} \%$ pristine $\alpha-Z r P, H A \_\alpha-Z r P, D G A \_\alpha-Z r P$, and OA_ $\alpha-Z r P$ nanosheets. 
HA_ $\alpha$-ZrP and DGA_ $\alpha$-ZrP nanosheets, no significant improvement in friction reduction is observed within $5,000 \mathrm{~s}$ compared to that for pure mineral oil, which is attributed to their poor dispersibilities. Subsequently, the COF values for HA_ $\alpha$-ZrP and DGA_ $\alpha$-ZrP nanosheets gradually drop to $\sim 0.07$ and $\sim 0.08$ respectively, which are $\sim 22 \%$ and $\sim 11 \%$ lower than that of pure mineral oil, indicating that both HA_ $\alpha-Z r P$ and DGA_ $\alpha-Z r P$ nanosheets show minor improvement in COF reduction. On the other hand, the COF for the mineral oil containing OA_ $\alpha-Z r P$ nanosheets rapidly decreases from $\sim 0.14$ to $\sim 0.05$ within $5,000 \mathrm{~s}$, which can be attributed to their excellent miscibilities with mineral oil molecules. After 5,000 s of friction, the COF stabilizes at $\sim 0.05$ until the end of the test, which is $\sim 47 \%$ smaller than that for pure mineral oil, indicating that high lubrication can be achieved by the addition of OA_ $\alpha-Z r P$ nanosheets to pure mineral oil.

The wear scars on the steel ball after tribological tests were investigated by SEM; the SEM images are shown in Fig. 11. The wear scars formed in the presence of pure mineral oil (Fig. 11(a)) reveal that the mating surfaces are severely damaged in the friction process, indicating strong interaction between the friction pairs for pure mineral oil. The SEM images of the WSD and wear scars on the steel ball for mineral oil dispersions with $1.0 \mathrm{wt} \%$ pristine and DGA_ $\alpha-\mathrm{ZrP}$ nanosheets are presented in Figs. 11(b) and 11(d). The WSDs for the samples are $\sim 20 \%$ (pristine $\alpha-\mathrm{ZrP}$ nanosheets) and $\sim 39 \%$ (DGA_ $\alpha$-ZrP nanosheets) higher than that for pure mineral oil, which are possibly due to their poor dispersion stabilities in mineral oil. For DGA_ $\alpha-Z r P$ nanosheets, the steel ball surface is more worn than that for pristine $\alpha-\mathrm{ZrP}$ nanosheets because of the presence of intercalated amine molecules. DGA is a polar molecule, which can aggravate crack expansion, resulting in an increase in the wear loss amount [38]. Unlike those for the poorly dispersed samples, the WSDs for the well-dispersed oils with HA_ $\alpha$-ZrP nanosheets (Fig. 11(c)) and OA_ $\alpha-Z r P$ nanosheets (Fig. 11(e)) are $\sim 11 \%$ and $\sim 28 \%$ lower than that for pure mineral oil, respectively. Moreover, the wear scars for the well-dispersed $\alpha-\mathrm{ZrP}$ nanosheets are smoother than those for the poorly dispersed samples. This is due to the high miscibility of the well-dispersed nanosheets with mineral oil molecules,
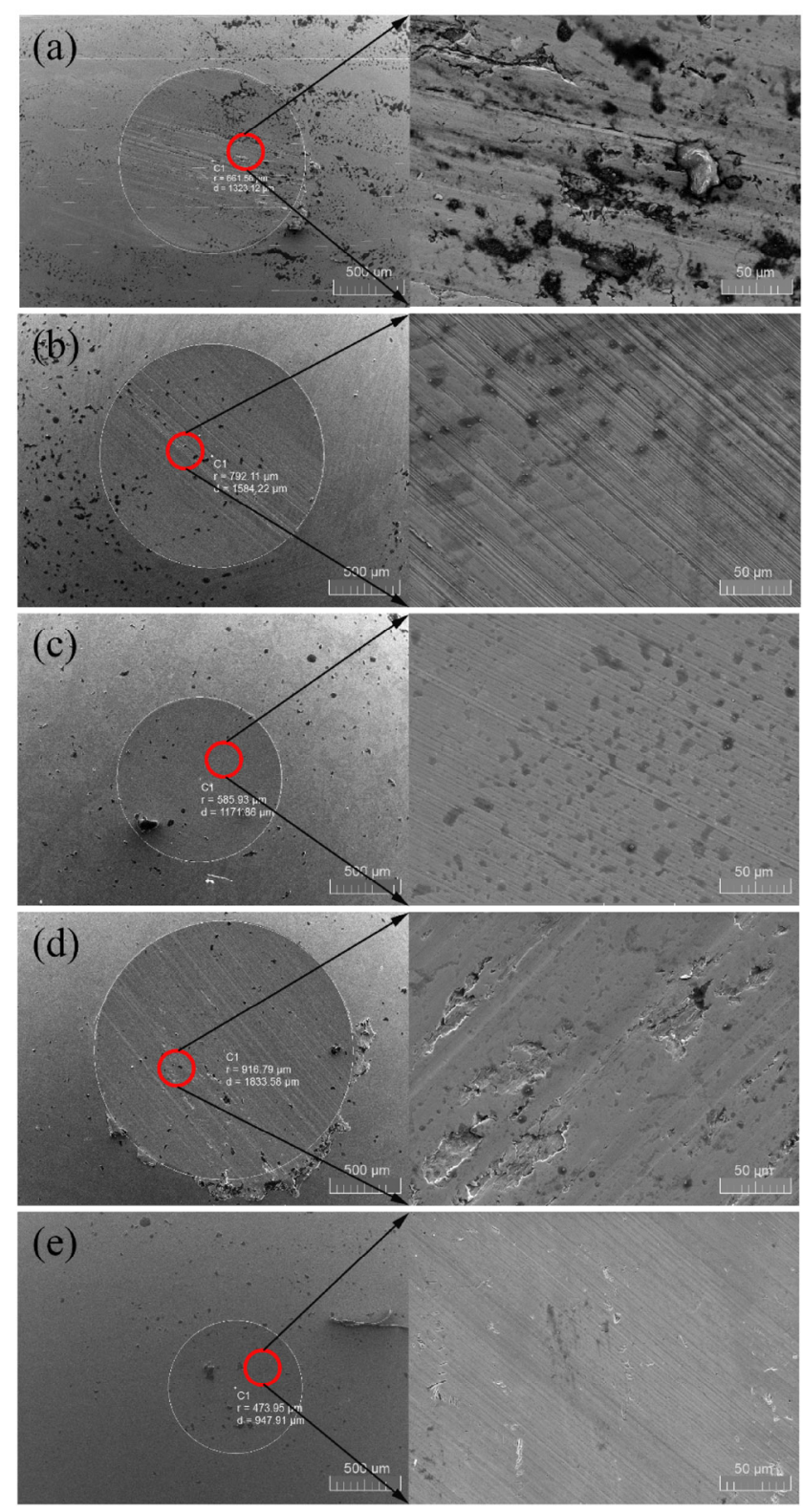

Fig. 11 SEM images of the steel ball after the tribological tests: (a) pure mineral oil and mineral oil containing $1.0 \mathrm{wt} \%$, (b) pristine $\alpha-Z r P$ nanosheets, (c) HA_ $\alpha-Z r P$ nanosheets, (d) DGA_ $\alpha-Z r P$ nanosheets, and (e) OA_ $\alpha$-ZrP nanosheets. Left: low-magnification images (for WSD comparison), and right: high-magnification images (for surface topological analysis).

which allows them to enter the contact area and deposit on the surface valleys, leading to asperity and WSD reduction.

\subsection{Friction-reduction and anti-wear mechanisms}

The proposed friction-reduction and anti-wear 
mechanisms for pristine and amine-intercalated $\alpha-\mathrm{ZrP}$ nanosheets dispersed in mineral oil are as follows. Firstly, the tribological performances of the prepared lubricating oils are mainly determined by the dispersion state of nanosheets in mineral oil (Fig. 6), which is illustrated in Fig. 12(a). The well-dispersed nanosheets can readily flow into the contact area because of their strong interaction with the mineral oil molecules and nanoscale sizes, preventing the direct contact of friction pairs and moderately smoothening the metal asperities, which leads to the formation of a smooth surface and decreased wear damages [16, 39, 40]. On the other hand, it is difficult for aggregated nanosheets to enter the friction area because of their large sizes and poor dispersion. Besides, large aggregates may act as grits, which can severely damage the friction pairs and lead to wear damage increase. Secondly, the COF for the mineral oil with OA_ $\alpha-Z r P$ nanosheets (Fig. 10) is consistently lower than that for pure mineral oil. This is attributed to the fact that OA_ $\alpha-\mathrm{ZrP}$ nanosheets dispersed in mineral oil can be easily exfoliated under shear stress owing to their large interlayer spacing, leading to a considerable reduction in the COF. Similar lubricating behaviors have also been observed for graphite and its derivatives [41, 42]; the corresponding mechanism is presented in Fig. 12(b). Lastly, our previous nano-lubrication study shows that zirconium phosphate nanoplatelets in oils do not form protective layers on rubbing surfaces during friction under our testing conditions [43], and the mechanisms involved are polishing, sliding, and exfoliation, as illustrated in Fig. 12.

\section{Conclusions}

In conclusion, $2 \mathrm{D}$ layered $\alpha$-ZrP nanosheets modified with various amines were successfully synthesized to investigate their dispersion stabilities and tribological performances in mineral oil. The important results can be summarized as follows:

(1) The suitable dispersant for stabilization of $\alpha-\mathrm{ZrP}$ nanosheets in oil should be amphiphilic and have a reasonably long chain to allow the oil molecules to enter the interlayers.

(2) The COF and pin volume loss for the dispersion containing an optimized concentration (1.0 wt \%) of OA_ $\alpha-\mathrm{ZrP}$ nanosheets with relatively large aspect ratios are $47 \%$ and $75 \%$, lower than that for pure mineral oil, respectively; on the other hand, the addition of poorly dispersed nanosheets leads to minor decrease or even increase in friction and wear.

(3) The high dispersion state of nanosheets in mineral oil is responsible for the improvement of their tribological performances, which opens a new horizon to enhance the tribological properties via tuning the dispersion stabilities of nanomaterials in oils.

Our results show that the utilization of amphiphilic intercalating molecules with relatively long chains for 2D layered nanomaterials in oil dispersions can lead to high-efficiency and stable lubricating oils for practical applications. The detailed dispersiontribological property relationship based on nanomaterial size and structural effects will be systematically investigated and reported in the near future.

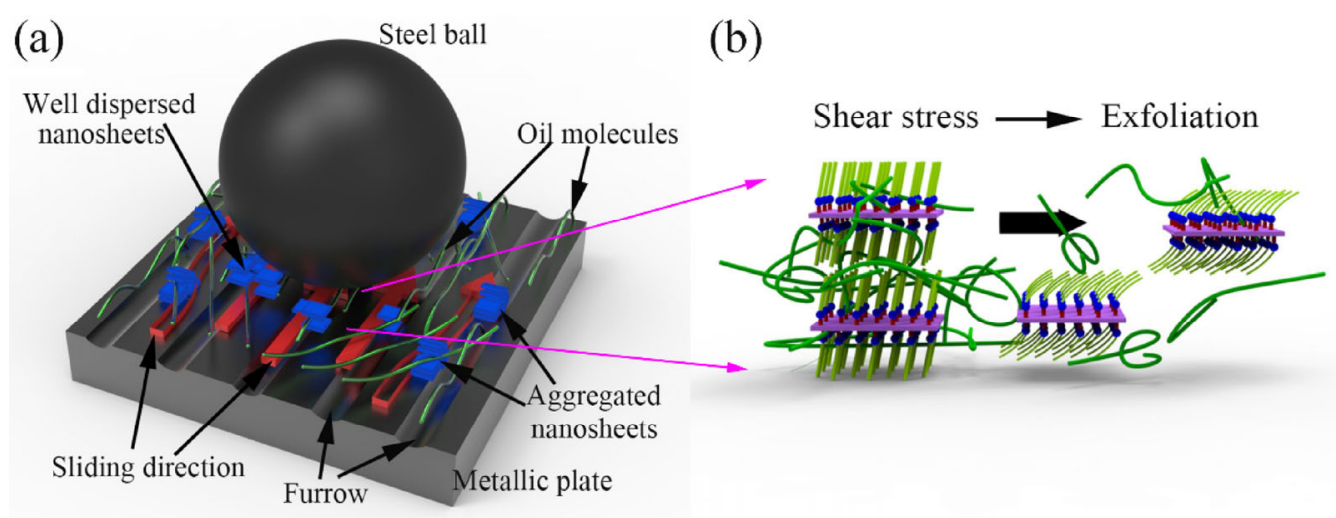

Fig. 12 Schematics showing (a) the effect of dispersion state on lubrication performance and (b) the exfoliation mechanism for the well-dispersed nanosheets. 


\section{Acknowledgements}

This work was supported by the start-up funding from the Southern University of Science and Technology (SUSTech), "The Recruitment Program of Global Youth Experts of China", and the Foundation of Shenzhen Science and Technology Innovation Committee (Grant Nos. JCYJ20160315164631204 and KQJSCX20170726145415637). Authors are also thankful to Mrs. Sixia Hu for the XRD training.

Open Access: This article is licensed under a Creative Commons Attribution 4.0 International License, which permits use, sharing, adaptation, distribution and reproduction in any medium or format, as long as you give appropriate credit to the original author(s) and the source, provide a link to the Creative Commons licence, and indicate if changes were made.

The images or other third party material in this article are included in the article's Creative Commons licence, unless indicated otherwise in a credit line to the material. If material is not included in the article's Creative Commons licence and your intended use is not permitted by statutory regulation or exceeds the permitted use, you will need to obtain permission directly from the copyright holder.

To view a copy of this licence, visit http://creativecommons.org/licenses/by/4.0/.

\section{References}

[1] Holmberg K, Andersson P, Erdemir A. Global energy consumption due to friction in passenger cars. Tribol Int 47: 221-234 (2012)

[2] Cai M R, Guo R S, Zhou F, Liu W M. Lubricating a bright future: Lubrication contribution to energy saving and low carbon emission. Sci China Technol Sci 56(12): 2888-2913 (2013)

[3] Byerlee J. Friction of rocks. Pure Appl Geophys 116(4-5): 615-626 (1978)

[4] He X L, Xiao X P, Choi H, Díaz A, Mosby B, Clearfield A, Liang H. $\alpha$-Zirconium phosphate nanoplatelets as lubricant additives. Colloids Surf A Physicochem Eng Aspects 452: 32-38 (2014)

[5] Tang Z L, Li S H. A review of recent developments of friction modifiers for liquid lubricants (2007-present). Curr Opin Solid State Mater Sci 18(3): 119-139 (2014)

[6] Mäkiharju S A, Perlin M, Ceccio S L. On the energy economics of air lubrication drag reduction. Int J Nav Arch Ocean Eng 4(4): 412-422 (2012)

[7] Boerzel P, Bronstert K, Hovemann F. Oil additives, maleic anhydride product. U.S. Patent 4152 499, May, 1979.

[8] Qu J, Truhan J J, Dai S, Luo H, Blau P J. Ionic liquids with ammonium cations as lubricants or additives. Tribol Lett 22(3): 207-214 (2006)

[9] Bermúdez M D, Jiménez A E, Sanes J, Carrión F J. Ionic liquids as advanced lubricant fluids. Molecules 14(8): 2888-2908 (2009)

[10] Wu Y Y, Tsui W C, Liu T C. Experimental analysis of tribological properties of lubricating oils with nanoparticle additives. Wear 262(7-8): 819-825 (2007)

[11] Spikes H. Low- and zero-sulphated ash, phosphorus and sulphur anti-wear additives for engine oils. Lubricat Sci 20(2): 103-136 (2008)

[12] Xu Y, Hu E Z, Hu K H, Xu Y F, Hu X G. Formation of an adsorption film of $\mathrm{MoS}_{2}$ nanoparticles and dioctyl sebacate on a steel surface for alleviating friction and wear. Tribol Int 92: 172-183 (2015)

[13] Yadgarov L, Petrone V, Rosentsveig R, Feldman Y, Tenne $\mathrm{R}$, Senatore A. Tribological studies of rhenium doped fullerene-like $\mathrm{MoS}_{2}$ nanoparticles in boundary, mixed and elasto-hydrodynamic lubrication conditions. Wear 297(1-2): 1103-1110 (2013)

[14] Bhushan B, Israelachvili J N, Landman U. Nanotribology: Friction, wear and lubrication at the atomic scale. Nature 374(6523): 607-616 (1995)

[15] Chen Y F, Zhang Y J, Zhang S M, Yu L G, Zhang P Y, Zhang Z J. Preparation of nickel-based nanolubricants via a facile in situ one-step route and investigation of their tribological properties. Tribol Lett 51(1): 73-83 (2013)

[16] Liu G, Li X, Qin B, Xing D, Guo Y, Fan R. Investigation of the mending effect and mechanism of copper Nano-particles on a tribologically stressed surface. Tribol Lett 17(4): 961-966 (2004)

[17] Popa I, Gillies G, Papastavrou G, Borkovec M. Attractive and repulsive electrostatic forces between positively charged latex particles in the presence of anionic linear polyelectrolytes. J Phys Chem B 114(9): 3170-3177 (2010)

[18] Yu W, Xie H Q. A review on nanofluids: Preparation, stability mechanisms, and applications. J Nanomater 2012: 435873 (2012)

[19] Song H J, Wang B, Zhou Q, Xiao J X, Jia X H. Preparation and tribological properties of $\mathrm{MoS}_{2} /$ graphene oxide composites. Appl Surf Sci 419: 24-34 (2017)

[20] Lee C G, Hwang Y J, Choi Y M, Lee J K, Choi C, Oh J M. A study on the tribological characteristics of graphite nano lubricants. Int J Precis Eng Manuf 10(1): 85-90 (2009) 
[21] Clearfield A, Stynes J A. The preparation of crystalline zirconium phosphate and some observations on its ion exchange behaviour. J Inorg Nucl Chem 26(1): 117-129 (1964)

[22] Díaz A, Saxena V, González J, David A, Casañas B, Carpenter C, Batteas J D, Colón J L, Clearfield A, Hussain M D. Zirconium phosphate nano-platelets: A novel platform for drug delivery in cancer therapy. Chem Commun 48(12): 1754-1756 (2012)

[23] Saxena V, Diaz A, Clearfield A, Batteas J D, Hussain M D. Zirconium phosphate nanoplatelets: A biocompatible nanomaterial for drug delivery to cancer. Nanoscale 5(6): 2328-2336 (2013)

[24] Sun L Y, Boo W J, Sun D Z, Clearfield A, Sue H J. Preparation of exfoliated epoxy/ $\alpha$-zirconium phosphate nanocomposites containing high aspect ratio nanoplatelets. Chem Mater 19(7): 1749-1754 (2007)

[25] Zhang H, Chen L, Han X, Jiang F, Sun H Y, Sun D Z. Enhanced mechanical properties of Nylon6 nanocomposites containing pristine $\alpha$-zirconium phosphate nanoplatelets of various sizes by melt-compounding. RSC Adv 7(52): 32682-32691 (2017)

[26] Chen L, Sun D Z, Li J, Zhu G D. Exfoliation of layered zirconium phosphate nanoplatelets by melt compounding. Mater Des 122: 247-254 (2017)

[27] Li D D, Xie Y C, Yong H S, Sun D Z. Surfactant-assisted preparation of $\mathrm{Y}_{2} \mathrm{O}_{3}$-stabilized $\mathrm{ZrO}_{2}$ nanoparticles and their tribological performance in mineral and commercial lubricating oils. RSC Adv 7(7): 3727-3735 (2017)

[28] Ma H J, Zhang X S, Xu H. Tribological properties of layered A-zirconium phosphate as lithium grease additive. Asian J Chem 27(3): 1133-1137 (2015)

[29] Tindwa R M, Ellis D K, Peng G Z, Clearfield A. Intercalation of n-alkylamines by $\alpha$-zirconium phosphate. J Chem Soc Faraday Trans 81(2): 545-552 (1985)

[30] Alberti G. Syntheses, crystalline structure, and ion-exchange properties of insoluble acid salts of tetravalent metals and their salt forms. Acc Chem Res 11(4): 163-170 (1978)

[31] Zhang X S, Xu H, Zuo Z J, Lin Z, Ferdov S, Dong J X. Hydrothermal synthesis of copper zirconium phosphate

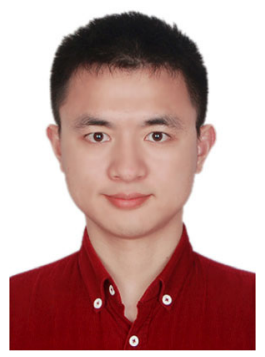

Feng JIANG. He received his bachelor degree in materials from Wuhan University, Wuhan, China. Then he obtained his master degree in materials science and engineering hydrate $\left[\mathrm{Cu}(\mathrm{OH})_{2} \mathrm{Zr}\left(\mathrm{HPO}_{4}\right)_{2} \cdot 2 \mathrm{H}_{2} \mathrm{O}\right]$ and an investigation of its lubrication properties in grease. ACS Appl Mater Interfaces 5(16): 7989-7994 (2013)

[32] Sun L Y, Boo W J, Sue H J, Clearfield A. Preparation of $\alpha$-zirconium phosphate nanoplatelets with wide variations in aspect ratios. New J Chem 31(1): 39-43 (2007)

[33] Alberti G, Costantino U. Recent progress in the intercalation chemistry of layered $\alpha$-zirconium phosphate and its derivatives, and future perspectives for their use in catalysis. J Mol Catal 27(1-2): 235-250 (1984)

[34] ASTM. ASTM Standard G 99 Standard test method for wear testing with a pin-on-disk apparatus. West Conshohocken (USA): ASTM, 2005.

[35] Cao Z, Sun L X, Cao X Q, He Y H. Synthesis and characterization of the layered zirconium phosphate and its intercalation study. Adv Mater Res 233-235: 1809-1813 (2011)

[36] Kim H N, Keller S W, Mallouk T E. Characterization of zirconium phosphate/polycation thin films grown by sequential adsorption reactions. Chem Mater 9(6): 1414-1421 (1997)

[37] Saunders A E, Ghezelbash A, Smilgies D M, Sigman M B, Korgel B A. Columnar self-assembly of colloidal nanodisks. Nano Lett 6(12): 2959 - 2963 (2006)

[38] Wen S Z, Huang P. Principles of Tribology. Singapore: John Wiley \& Sons Inc., 2012: 647-648.

[39] Hou K M, Gong P W, Wang J Q, Yang Z G, Wang Z F, Yang S R. Structural and tribological characterization of fluorinated graphene with various fluorine contents prepared by liquidphase exfoliation. RSC Adv 4(100): 56543-56551 (2014)

[40] Tao X, Zhao J Z, Xu K. The ball-bearing effect of diamond nanoparticles as an oil additive. $J$ Phys D-Appl Phys 29(11): 2932-2937 (1996)

[41] Fusaro R L, Sliney H E. Graphite fluoride $\left(\mathrm{CF}_{x}\right)_{n}-\mathrm{A}$ new solid lubricant. A S L E Trans 13(1): 56-65 (1970)

[42] Hills B A. Graphite-like lubrication of mesothelium by oligolamellar pleural surfactant. J Appl Physiol 73(3): 1034-1039 (1992)

[43] Han X, Yong H S, Sun D Z. Tuning tribological performance of layered zirconium phosphate nanoplatelets in oil by surface and interlayer modifications. Nanoscale Res Lett 12: 542 (2017)

from Joint Harbin Institute of Technology-Southern University of Science and Technology program, Shenzhen, Guangdong, China. His research interests mainly focus on the synthesis of nano-lubricants and their dispersion stability in lubricating oils. 


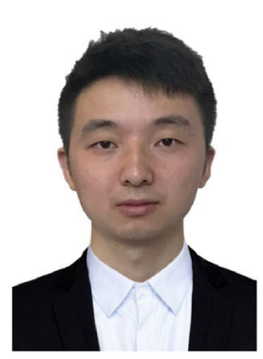

Haoyang SUN. He received his bachelor degree in materials science and engineering from Harbin Institute of Technology University, Harbin, China. Then he obtained his master degree in materials science and engineering from Joint

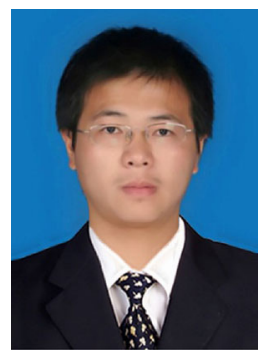

Lei CHEN. He received his bachelor degree in metallurgical engineering from Central South University, Changsha, China, his master degree in mechanical design and theory from Xiangtan University, Xiangtan, China, and his Ph.D. in mechanical

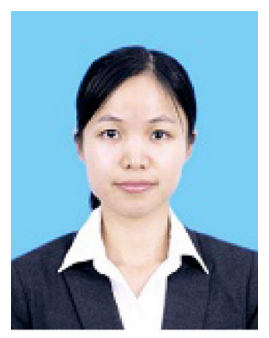

Fan LEI. She received her bachelor degree in material processing and control engineering from Changsha University of Science and Technology, Changsha, China, and Ph.D. degree in materials science from Sichuan

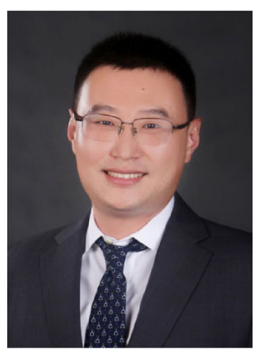

Dazhi SUN. He received his bachelor and master degrees in chemical engineering from Tsinghua University, Beijing, China, and his Ph.D. in materials science and engineering from Texas A\&M University, USA.
Harbin Institute of Technology-Southern University of Science and Technology program, Shenzhen, Guangdong, China. His research interests mainly focus on the synthesis of 2D materials, the physical modification of polymers, and the structure-property relationship of polymeric composites.

engineering from Central South University, Changsha, China, respectively. After his post-doc research at Southern University of Science and Technology, Shenzhen, China, he joined Dongguan University of Technology, Dongguan, China, as a lecturer. His research interests include polymer nanocomposites and micro injection molding technology.

University, Chengdu, China. She is currently a postdoctor in Southern University of Science and Technology, Shenzhen, China. Her research interests mainly focus on the structure-property relationship of polymer nanocomposites.

After his post-doc research at Brookhaven National Lab, he joined Southern University of Science and Technology, Shenzhen, China, as an associate professor. His research interests include polymers, nanomaterials, nanolubricating materials, and their industrial applications. 